\title{
Campanha Nacional de Combate ao Câncer do Colo Uterino: a contribuição do laboratório de anatomia patológica da Santa Casa de Misericórdia de Passos (MG)*
}

\author{
National Cervical Cancer Screening Program: the contribution of anatomic \\ pathology laboratory of Santa Casa de Misericórdia de Passos (MG)
}

\author{
Cristina Rubim Parentoni Costa ${ }^{1}$ e Paula Ávila Fernandes 2
}

\begin{abstract}
Resumo
O exame citológico de amostras cérvico-vaginais tem sido amplamente usado na prevenção e detecção precoce do carcinoma do colo uterino. $\mathrm{N}$ os países onde há programas de prevenção organizados têm-se conseguido diminuir as taxas de mortalidade desta doença. N o Brasil, a primeira Campanha $\mathrm{N}$ acional de Combate ao $\mathrm{C}$ âncer de Colo U terino foi realizada no período de agosto a setembro de 1998. No presente trabalho, avaliamos os resultados dos exames citopatológicos realizados durante esta Campanha no Laboratório de Anatomia Patológica da Santa Casa deM isericórdia de Passos (M G ). Foram realizados 2.905 exames colpocitológicos em mulheres na faixa compreendida entre 25 e 62 anos de idade, dos quais $16(0,54 \%)$ apresentaram algum tipo de alteração epitelial atípica. 0 maior número de exames foi procedente da cidade de Passos e a maior freqüência de exames ocorreu na faixa etária entre 36 e 49 anos de idade. Apesar da freqüência dos diagnósticos de células escamosas atípicas de significado indeterminado (ASC US) estar dentro dos valores propostos pela literatura para a relação ASCUS/N eoplasia Intraepitelial Cervical (NIC) de 1:16, é possível que alguns casos de infecção pelo Papiloma Vírus Humano (H PV) tenham sido diagnosticados como ASCUS.
\end{abstract}

Palavras-chave: neoplasias do colo uterino; prevenção \& controle; citodiagnóstico; epidemiologia; programas nacionais de saúde; Brasil.

\begin{abstract}
Cytological diagnosis of cervical smears have been used to prevent and detect early cervical carcinoma. In countries where a cervical cancer screening program is organized, the mortality rate due to cervical cancer is reduced. In Brazil, the first N ational Cervical Cancer Screening Program was carried out from August to September 1998. In the present study, the results of this Program at the city of Passos- M G are reported. Two thousand nine hundred and five (2905) cervical smears were analyzed, and $16(0,54 \%)$ showed some degree of epithelial or glandular atypical features. The highest number of cervical smears was from women between 36 and 49 years old. Although the frequency of atypical squamous cells of undetermined significance (ASCUS) was similar to that reported in the literature, with a relation ASCUS/ Cervical Intraepithelial N eoplasm (CIN) of 1:16, it is possible that some cases of H uman Papiloma Virus (H PV) had been diagnosed as ASCU S.
\end{abstract}

Key words: cervix neoplasms; prevention \& control; cytodiagnosis; epidemiology; national health programs; Brazil.

*Trabalho realizado no Laboratório de Anatomia Patológica da Santa Casa de M isericórdia de Passos (M G) e no D epartamento de Análises Clínicas e Toxicológicas da Faculdade de Farmácia da UFM G.

${ }^{1}$ Farmacêutica-Bioquímica, especialista em Citopatologia. Enviar correspondência para C.R.P.C. E-mail: crisrpcosta@minasnet.psi.br

${ }^{2}$ Professora doutora do D epartamento de Análises Clínicas e Toxicológicas, Faculdade de Farmácia, Universidade Federal de M inas Gerais, Belo H orizonte, M G - Brasil. 


\section{INTRO DUÇÃO}

D e acordo com as estimativas de incidência de câncer para 0 ano de 2002, o câncer de colo uterino deverá ser o terceiro mais freqüente, sendo superado pelo câncer de mama e pelo câncer de pele do tipo não melanótico. ${ }^{1}$

Em 1998, entre os meses de agosto a setembro, foi realizada no Brasil a Campanha $\mathrm{N}$ acional de Combate ao Câncer do Colo U terino, patrocinada pelo M inistério da Saúde (M S), tendo como principal objetivo realizar examescitológicos cérvico-vaginais na população feminina de 35 a 49 anos deidade. A coleta dos exames foi realizada nos postos de saúde públicos por médicos ginecologistas e enfermeiras treinadas. As amostras foram analisadas em laboratórios previamente cadastrados pelas Secretarias Estaduais de Saúde.

\section{REVISÃO DA LITERATURA}

No Brasil, a Campanha $\mathrm{N}$ acional de Combate ao Câncer de Colo U terino foi o primeiro programa de detecção e prevenção do câncer de colo uterino realizado com abrangência nacional. Antes da Campanha havia projetos regionais implantados em alguns Estados. 0 primeiro foi realizado em 1948 na U niversidade Federal do Rio de Janeiro (UFRJ), ${ }^{2}$ e em 1968 iniciou-se 0 Programa de Controle de $C$ âncer $C$ érvico-U terino de Campinas (PCCUC), com o objetivo principal de colocar sob controle em cinco anos $30 \%$ da população feminina exposta ao risco e em quinze anos aumentar a cobertura para até $90 \%$ da população. $\mathrm{N}$ a implantação do PCCUC, as principais medidas adotadas foram a descentralização da coleta do exame citológico com aproveitamento de todos os locais de assistência médica e a centralização da execução do exame citopatológico, que propiciou redução de custos do programa com controle de qualidade adequado. De 1968 até 19940 Programa conseguiu, na região de C ampinas, reverter o câncer de colo uterino da fase de incurabilidade para a curabilidade. ${ }^{3} 0$ Programa de Campinas serviu de modelo para que a Secretaria de Estado da Saúde de São Paulo criasse, em 1986, o Programa de Controle de C âncer Cérvico-Uterino do Estado de São Paulo. De 1986 a 1990 o Programa citado conseguiu passar de uma cobertura de $8,38 \%$ para $30,06 \%$ da população de mulheres sexualmente ativas e com idade igual ou maior que 20 anos. ${ }^{4} \mathrm{~N}$ o norte do Estado do Rio de Janeiro, em 1987, iniciou-se o Projeto Campos, com o objetivo não só de ampliar a cobertura da população pelo exame citopatológico mas também de acompanhar as pacientes no tratamento em casos de citologias atípicas. $^{3} 0$ Governo Brasileiro, incentivado pela Conferência $M$ undial de $M$ ulheres realizada na $C$ hina em 1995, desenvolveu um Programa $N$ acional de Rastreamento do C âncer do Colo U terino, chamado de Programa Viva M ulher. 0 projeto-piloto deste Programa foi implantado em cinco municípios representando cidades de cada região do Brasil, e em um Estado (Sergipe). ${ }^{5}$ A primeira fase de intensificação do Programa Viva Mulher ocorreu em 1998, dando origem à Campanha N acional de Combate ao Câncer de Colo U terino, na qual 5.398 municípios brasileiros foram envolvidos. No Paraná, foram colhidas amostras cervicais de 857.786 mulheres no período de outubro de 1997 a setembro de 1999. O s resultados negativos foram da ordem de $81,46 \%$. Em 2,03\% dos casos foi encontrado algum grau de atipia glandular ou epitelial. Carcinomas invasivos foram detectados em 0,04\% dos casos. $^{6}$

Em Passos, o Laboratório de Anatomia Patológica da Santa C asa de M isericórdia iniciou suas atividades em 1980. Apesar de não haver um Programa de Prevenção de Câncer do Colo U terino sistematizado, os exames citológicos têm sido coletados em postos de saúde municipais por médicos ginecologistas e enfermeiras.

Pretende-se neste trabalho, verificar a contribuição do Laboratório de Anatomia Patológica da Santa Casa de M isericórdia de Passos na Campanha Nacional de Combate ao Câncer de Colo U terino de 1998, mediante análise e discussão dos resultados dos exames citopatológicos.

\section{MATERIAL E MÉTO DOS}

Foram revistos 2.905 laudos citológicos de amostras cérvico-vaginais coletadas em postos de saúde públicos na cidade de Passos e em outras 20 cidades da região e enviados ao L aboratório de Anatomia Patológica da Santa C asa de M isericórdia de Passos no período de agosto a setembro de 1998. As amostras foram coletadas por ginecologistas e enfermeiras utilizando kits de coleta contendo espéculo, escova para coleta de material do canal endocervical, espátula de madeira e lâmina. Para cada paciente foi preenchido um formulário de requisição do exame citológico com dados pessoais e informações da coleta.

Durante a revisão dos laudos foram revistas as seguintes variáveis: municípios de coleta, idade das pacientes, avaliação da amostra e diagnóstico citológico. Para avaliação da amostra e diagnóstico citológico, os dados foram agrupados nas faixas etárias de 25 a 35 anos, de 36 a 49 anos e de 50 ou mais anos e, posteriormente, computados de acordo com a descrição do formulário de resultado de exame citológico fornecido pelo M inistério da Saúde. 


\section{RESULTADO $S$}

Durante a Campanha, as amostras foram coletadas em postos de saúde públicos em cidades da região de Passos, sudoeste de M inas Gerais, e enviadas para o Laboratório de Anatomia Patológica da Santa Casa de M isericórdia de Passos. 0 número de exames realizados por cada município está descrito na Tabela 1.

N os 2.905 laudos citológicos revistos, a idade das pacientes variou de 25 a 62 anos e a maior freqüência de exames ocorreu na faixa etária entre 36 e 49 anos.
Em 51,53\% dos casos a amostra dos esfregaços foi satisfatória. Em 46,75\% a amostra foi satisfatória, porém limitada pela ausência de células representativas da junção escamo-colunar (JEC), e em 1,72\% dos casos a amostra dos effregaços foi considerada insatisfatória. A Tabela 2 mostra a distribuição dos casos por faixa etária segundo os diagnósticos citológicos. A porcentagem de casos com anormalidades em células epiteliais foi pequena (Tabela 3). D os 16 casos com alteração em células epiteliais, 10 foram coletados na cidade de Passos, o que resulta numa frequêencia, nesta cidade, de $0,79 \%$ de casos.

Tabela 1. Número de exames realizados por município.

\begin{tabular}{|l|c|}
\hline \multicolumn{1}{|c|}{ Municípios } & Exames realizados \\
\hline Alpinópolis & 151 \\
\hline Bom Jesus da Penha & 91 \\
\hline Capetinga & 52 \\
\hline Capitólio & 87 \\
\hline Cássia & 119 \\
\hline Claraval & 02 \\
\hline Delfinópolis & 86 \\
\hline Doresópolis & 06 \\
\hline Fortaleza de Minas & 99 \\
\hline Guapé & 60 \\
\hline Itamogi & 21 \\
\hline Itaú de Minas & 266 \\
\hline Jacuí & 106 \\
\hline Passos & 1258 \\
\hline Piui & 102 \\
\hline Pratápolis & 121 \\
\hline São João Batista do Glória & 172 \\
\hline São José da Barra & 25 \\
\hline São Roque de Minas & 71 \\
\hline São Tomás de Aquino & 01 \\
\hline Vargem Bonita & 09 \\
\hline TOTAL & 2905 \\
\hline
\end{tabular}

Tabela 2. Distribuição dos casos por faixa etária segundo os diagnósticos citológicos.

\begin{tabular}{|c|c|c|c|c|}
\hline & \multicolumn{3}{|c|}{ Faixa etária (anos) } & \\
\hline Diagnósticos & $21-35$ & $36-50$ & $>51$ & ${\text { Total }(\%)^{*}}^{*}$ \\
\hline dentro dos limites da normalidade & 254 & 1252 & 5 & $1511(52,01)$ \\
\hline inflamação & 155 & 1038 & 15 & $1208(41,58)$ \\
\hline metaplasia escamosa & 29 & 275 & 1 & $305(10,50)$ \\
\hline atrofia com inflamação & 0 & 29 & 6 & $35(1,20)$ \\
\hline alterações em células epiteliais & 1 & 15 & 0 & $16(0,54)$ \\
\hline
\end{tabular}

*Como mais de um diagnóstico pode ser emitido em um esfregaço (com exceção da categoria "dentro dos limites da normalidade"), a soma dos percentuais excede $100 \%$. 
Tabela 3. Freqüência de alterações em células epiteliais.

\begin{tabular}{|l|c|c|}
\hline \multicolumn{1}{|c|}{ Diagnóstico } & $\begin{array}{c}\text { Número } \\
\text { de casos }\end{array}$ & (\%) \\
\hline ASCUS & 07 & $0,24 \%$ \\
\hline AG US & 02 & $0,07 \%$ \\
\hline NIC I & 04 & $0,14 \%$ \\
\hline NIC II & 01 & $0,03 \%$ \\
\hline NIC III & 01 & $0,03 \%$ \\
\hline Carcinoma escamoso invasivo & 01 & $0,03 \%$ \\
\hline Total & 16 & $0,54 \%$ \\
\hline
\end{tabular}

\section{DISCUSSÃO}

Durante a Campanha $\mathrm{N}$ acional de Combate ao Câncer do Colo U terino na região estudada, o maior número de amostras foi procedente da cidade de Passos (1.258 exames), que é a maior cidade da região. Em 1996, segundo dados da Agência Passos do Instituto Brasileiro de Geografia e Estatística, a população feminina da cidade entre 25 e 64 anos era de 21.677 mulheres. D este total, apenas $5,8 \%$ das mulheres procuraram os ambulatórios municipais para realizar 0 exame citológico durante a C ampanha, de acordo com os dados registrados no Laboratório de Anatomia Patológica da Santa C asa de M isericórdia de Passos. Este percentual é inferior à cobertura estimada de $8 \%$ das mulheres acima de 20 anos de idade com base na coleta em serviço público. ${ }^{7} \mathrm{~N}$ o entanto, a possibilidade da cobertura ter sido maior não fica excluída uma vez que alguns exames podem ter sido realizados por laboratórios privados da região. 0 maior número de exames foi realizado em mulheres na faixa etária de 36 a 49 anos, estando de acordo com a faixa etária estabelecida como prioridade pelo M inistério da Saúde.

$\mathrm{Na}$ cidade de Passos, o Programa de Assistência Integral à Saúde da M ulher está implantado desde 1992 nos dez ambulatórios médicos existentes com coleta de exame cérvico-vaginal. A procura das pacientes por este serviço de saúde regularmente oferecido na cidade poderia explicar o pequeno número de pacientes que realizaram exame citológico dentro do programa da Campanha. Acredita-se que a maioria dos casos revistos neste trabalho era de pacientes que já haviam feito pelo menos um exame preventivo. $\mathrm{N}$ ão foi possível contabilizar o número de casos novos porque muitas requisições não continham informações sobre a coleta ou estavam preenchidas de forma duvidosa.

No presente trabalho, a percentagem de casos com algum grau de anormalidade em células epiteliais foi pequena $(0,54 \%)$. D urante a $\mathrm{C}$ ampanha $\mathrm{N}$ acional de Combate ao Câncer de Colo U terino realizada nos 5.389 municípios brasileiros, foram realizados 3.177 .740 exames citopatológicos, e deste total, 60.662 (1,90\%) apresentaram algum tipo de anormalidade. ${ }^{8}$ Valores baixos como os encontrados no nosso trabalho, poderiam ser justificados pela orientação sistemática de prevenção e controle da população feminina, não só em Passos (que é a maior cidade pesquisada), mas também em outras cidades da região. Além disso, outros dois aspectos devem ser considerados: o pequeno número de laudos revistos e um número relativamente grande de amostras classificadas como satisfatória porém limitada pela ausência de células da JEC detectadas no nosso estudo. Este último item é importante uma vez que a freqüência de lesões pré-neoplásicas é maior em effregaços com representação das células da JEC. ${ }^{9}$

D eve-se enfatizar, no entanto, que as anormalidades encontradas no nosso trabal ho em $0,54 \%$ dos casos representam alterações epiteliais com comportamento biológico muito distintos, uma vez que estão incluídos desde diagnósticos citológicos de ASCUS e atipias glandulares de significado indeterminado (AGUS) até de carcinoma invasor. Apesar de sete dos 16 casos com anormalidades epiteliais terem sido diagnosticados como ASCUS, a relação entre casos de ASCU S/N IC ainda está dentro do proposto por alguns autores, onde a freqüência deASCUS não deveexceder de duas a trêsvezes o número de casos de NIC. ${ }^{10}$ Laboratórios americanos de Universidades, Instituições G overnamentais e Federais têm demonstrado as menores taxas de relação de diagnósticos ASCUS/NIC, em torno de 1:1, 1:1 e 0:8, respectivamente. ${ }^{11} \mathrm{~N}$ o nosso trabalho, encontramos sete casos de ASCUS e seis de NIC (relação de 1:16). Ao analisarmos nossos resultados, verificamos que não foi detectado nenhum caso de infecção por H PV. Casos de infecção por esteagente são rotineiramente diagnosticados no Laboratório da Santa Casa de Passos. No entanto, é possível que este achado esteja relacionado com a faixa etária das pacientes. Sabe-se que a prevalência da infecção por HPV é maior em pacientes mais jovens, ${ }^{12}$ que não foram priorizadas nesta $\mathrm{C}$ ampanha. $\mathrm{O}$ utro aspecto a ser considerado é que prováveis casos de infecção por H PV tenham sido diagnosticados como ASCU S. Alguns padrões citológicos (como por exemplo, coilocitose leve e paraceratose atípica) podem estar associados ao diagnóstico de ASCUS ${ }^{13}$ e que, alguns deles representariam infecção por H PV. A partir de resultados de diversos trabalhos de seguimento clínico de pacientes com diagnóstico de ASCUS, ${ }^{14}$ estima-se que aproximadamente um terço destas pacientes apresentarão lesões escamosas intra-epiteliais (incluindo os casos de H PV). N o nosso trabalho, somente 0 acompanhamento das pacientes com a realização de novos exames citopatológicos, colposcópicos e histopatológicos poderia 
esclarecer o diagnóstico definitivo.

Considerando que um programa de rastreamento pode ser avaliado através de vários fatores, dentre eles 0 número de pessoas examinadas, a prevalência da doença pré-clínica detectada e a proporção de casos positivos trazidos para diagnóstico definitivo e tratamento, ${ }^{15}$ esperamos que estes resultados iniciais aqui registrados possam contribuir para o planejamento de novas ações de saúde visando à prevenção do câncer de colo uterino. D entre as novas ações, destacamos: 1) o preenchimento correto do formulário de requisição do exame citológico, a boa qualidade das amostras coletadas e 0 acompanhamento adequado das pacientes; 2) a revisão da faixa etária das pacientes abordadas na Campanha, tendo em vista o acometimento de lesões precursoras do câncer de colo uterino em mulheres cada vez mais jovens; e finalmente, 3) planejar a Campanha de forma que suas ações venham sempre somar-se às ações de um programa de prevenção já existente.

\section{CONCLUSÕ ES}

0 maior número de exames foi procedente da cidade de Passos onde já havia coleta sistematizada nos postos de saúde públicos. N esta cidade, 5,8\% das mulheres entre 25 e 64 anos realizaram o exame citológico, em ambulatórios municipais, durante a Campanha. 0 maior número de exames ocorreu na faixa etária entre 36 e 49 anos. A porcentagem de casos com algum grau de anormalidade em células epiteliais foi pequena $(0,54 \%)$, refletindo, possivelmente, 0 trabalho sistemático de prevenção e controle da população feminina realizado na região estudada. A pesar da freqüência dos diagnósticos de ASC US estar dentro dos valores propostos pela literatura, com relação ASCUS/ NIC de 1:16, é possível que alguns casos de infecção por HPV tenham sido diagnosticados como ASCUS.

\section{REFERÊN CIAS BIBLIO G RÁFICAS}

1. K ligerman J. Estimativas sobrea incidência emortalidade por câncer no Brasil - 2002 [editorial]. Rev Bras Cancerol 2002;48(2):175-9.

2. PasqualleteH A, Santos PL, Teixeira, EC. Projeto piloto de prevenção decâncer decérvix uterino napopulação operária deuma fábrica do Estado do Rio deJaneiro. J Bras Ginecol 1987;97:468-72.

3. Abreu E, Jaconianni M, Lavor M F, LopesER, M ello RC, LemosM $R$, et al. Controle do câncer cérvico-uterino: um desafio. J Bras Ginecol 1991;101(6):243-7.

4. Pinotti JA, Carvalho JP, N isidaACT. Controle do câncer cervical no Brasil. Rev G inecol O bstet 1994;5:5-10.

5. M oraes M F. ProgramaViva M ulher [editorial]. Rev Bras Cancerol 1997;43(2):103-5.

6. Torres LFB, Totsugui JT, N oronha L, Pinto AP, Araújo SR, Collaço $L M$. The cervical cancer screening program of Paraná, Brazil. Patologia 2000;38:14.

7. M inistério da Saúde (Brasil). Controle do câncer cérvicouterino e demama: normas e manuais técnicos. Braślia: Centro deD ocumentação do M inistério da Saúde; 1989.

8. Instituto $\mathrm{N}$ acional de $\mathrm{C}$ âncer (Brasil). Recomendações básicas para o controle do câncer do colo do útero no Brasil: normase recomendações do Instituto $\mathrm{N}$ acional de $\mathrm{C}$ âncer/ M S. Rev Bras C ancerol 2000;46(1):23-33.

9. Shirata N K, PereiraSM M , CavaliereM J, Longatto Filho A, U tagawa M L, Shih LW, et al. Celularidade dos esfregaços cervicovaginais: importância em programas de garantia de qualidadeem citopatologia.J BrasGinecol 1998;108:63-6.

10. Kurman RJ, Solomon D. 0 Sistema Bethesda para o relato de diagnóstico citológico cérvico-vaginal. Rio deJ aneiro: Revinter, 1997.

11. D avey D D, N ielsen M L, N aryshkin S, Robb JA, C ohen T, KlineT S. Atypical squamouscells of undetermined significance. Current laboratory practices of participants in the College of American Pathologistsinterlaboratory comparison program in cervico-vaginal citology. Arch Pathol Lab M ed 1996;120:440-4.

12. N onnenmacher B, Breitenbach V, Villa LL, Prolla JC, Bozzetti M C. Identificação do papilomavírus humano por biologiamolecular em mulheresassintomáticas. Rev Saúde Pública 2002;36:95-100.

13. C rum C, C ibas SE. N on diagnostic squamous atypia. In: Crum C, Cibas SE, Lee RK. Pathology of early cervical neoplasia. 1st ed. Boston: Churchil Livingstone; 1997.

14. Boerner SL, Katz RL. O n theorigins of "atypical squamous cells of undetermined significance": the evolution of a diagnostic term. Adv Anat Pathol 1997;4:221-32.

15. ReisAFF, CostaM CE, Almeida, N C. Prevenção do câncer cérvico-uterino: princípiosepidemiológicos eavaliação dos programas descreening. J Bras Ginecol 1992;102:445-7. 